\title{
Aberrant Expression of Syndecan-1 in Cervical Cancers
}

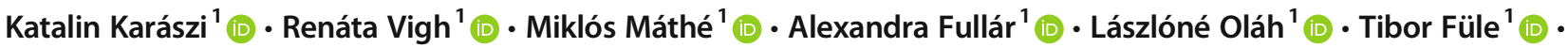 \\ Zoltán Papp ${ }^{2,3}$ (D) Illona Kovalszky ${ }^{1}$ (D)
}

Received: 21 April 2020 / Accepted: 28 April 2020 / Published online: 10 May 2020

(C) The Author(s) 2020

\begin{abstract}
Syndecan-1, is a transmembrane heparan/chondroitin sulfate proteoglycan necessary for cell-cell and cell-matrix interactions. Its decreased level on the cell surface correlates with poor prognosis in several tumor types. Aberrant stromal localization of syndecan1 is also considered an unfavorable prognostic factor in various human malignancies. In the presented work the question was addressed if changes in syndecan-1 expression are related to the prognosis of cervical cancer. Immunohistochemistry for syndecan1 extracellular domain was performed on surgical specimens of primary cervical cancer. To follow the communication between tumor cells and stromal fibroblasts, their mono-and co-cultures were studied, detecting the expression of syndecan-1, smooth muscle actin, vimentin, and desmin. Immunohistochemistry of tumorous specimens revealed that while cell surface syndecan-1 expression was reduced on cancer cells, it appeared on the surface of tumor-associated fibroblasts. Until year 7, the cohort with high cell surface syndecan-1 expression had significantly longer survival. No difference in the same time-period could be detected when stromal syndecan-1 expression was analyzed. In vitro analysis revealed, that tumor cells can induce syndecan-1 expression on fibroblast, and fibroblasts showed that fibroblast-like cells are built by two cell types: (a) syndecan-1 positive, cytokeratin negative real fibroblasts, and (b) syndecan-1 and cytokeratin positive epithelial-mesenchymal transformed tumor cells. Syndecan-1 on the surface of cancer cells appears to be a positive prognostic marker. Although syndecan-1 positive fibroblasts promote tumor cell proliferation in vitro, we failed to detect their cancer promoting effect in vivo.
\end{abstract}

Keywords Syndecan-1 $\cdot$ Cervical cancer $\cdot$ Survival analysis $\cdot$ Cancer-associated fibroblasts $\cdot$ Extracellular matrix remodeling

\section{Introduction}

In spite of recent advances in prevention, early diagnosis, effective screening and treatment programs, cervical cancer is still associated with the fourth highest mortality rate in women oncology worldwide [1,2].

Ilona Kovalszky

kovalszky.ilona@med.semmelweis-univ.hu;

kovalelastic@gmail.com

Katalin Karászi

tika0604@gmail.com

Renáta Vigh

vighreni@gmail.com

Miklós Máthé

mathemiklos@gmail.com

Alexandra Fullár

fullarsz@gmail.com

Lászlóné Oláh

olah.nagy.julianna@gmail.com
Stromal cells and extracellular matrix (ECM) elements have tremendous impact on the nature of cancer. The tumor cells remodel their local surrounding environment by the production of stimulatory factors and cytokines forming the tumorous neostroma which contains cancer-associated fibroblasts (CAFs), endothelial cells and inflammatory cells [3].

Tibor Füle

251tibor@gmail.com

Zoltán Papp

pzorvosihetilap@maternity.hu

1 1st Department of Pathology and Experimental Cancer Research, Semmelweis University, Üllöi út 26, Budapest H-1085, Hungary

2 1st Department of Obstetrics and Gynecology, Semmelweis University, H-1082 Budapest, Hungary

Maternity Obstetrics and Gynecology Private Clinic, H-1126 Budapest, Hungary 
CAFs producing matrix proteins in increased quantity and altered quality are important players in ECM remodeling [4]. ECM plays a key role in tumor cell invasion and metastasis. By producing metalloproteases the invading cells degrade and pass through the basement membrane. This event opens up the gate for further migration of tumor cells through the remodeled interstitial matrix $[5,6]$.

Syndecans, a four-member family of proteins belonging to the group of integral membrane heparan sulfate proteoglycans (HSPGs), participate in cell-cell recognition and cell-matrix interactions [7-10]. Syndecan-1 (sdc1), a typical component of the epithelial cell, acts as growth factor reservoir or co-receptor for stimulatory signal transduction on the cell surface [7,9-11]. This protein molecule has a short cytoplasmic domain with four phosphorylation sites, a transmembrane and an extracellular domain; the latter bearing the heparan sulfate and chondroitin sulfate glycosaminoglycan chains responsible for growth factor binding [7, 12-15].

The role of syndecan-1 in various human tumors has been extensively investigated. Decrease of epithelial cell membrane syndecan-1 expression, observed in precancerous lesions of the oral cavity and uterine cervix, is regarded as a step towards malignant transformation [16-18]. Later on during the progress of tumor microevolution, the malignant clone apparently takes advantage of the loss of cell surface syndecan-1, as observed through the connection between decreased cell surface syndecan-1 levels and unfavorable prognosis in head and neck tumors and gastric cancers [19-21]. The extent of membrane syndecan-1 loss correlates with the grade of cervical cancers and also presumably with the presence of lymph node metastasis, without showing correspondence with other main clinical parameters [20, 22-24].

Normally, syndecan- 1 expression is limited to the epithelia and certain B-lymphocytes, including immature B-cells and plasma cells [25]. Nevertheless, fibroblasts in the stroma of tumors may also express syndecan-1 [26]. This tumor-induced aberrant stromal syndecan-1 expression is an unfavorable prognostic factor in mammary and gastric malignancies, in head and neck squamous cell cancers as well as other tumors [27-33].

Here, we investigated the significance of pathological syndecan-1 expression and localization in cervical cancers and correlated syndecan-1 presence with the 15 -year survival rate.

\section{Materials and Methods}

\section{Sample Collection}

Paraffin sections of Wertheim hysterectomy for survival study were received between 2000 and 2002 from the 1st
Department of Obstetrics and Gynecology of Semmelweis University (Budapest, Hungary). From 2004 fresh surgical specimens used for tissue microarray and tissue culture work obtained from radical Wertheim hysterectomy were sent for routine pathology service to the 1 st Department of Pathology and Experimental Cancer Research from the Maternity Obstetrics and Gynecology Private Clinic and the 1st Department of Obstetrics and Gynecology of Semmelweis University (Budapest, Hungary). Surgical samples were collected after written informed consent and used according to the instructions of Semmelweis University Regional and Institutional Committee of Science and Research Ethics (TUKEB permit number: 95/1999). Specimens and data were stored anonymously. The study conforms to the standards set by the Declaration of Helsinki. Table 1 summarizes the clinical data of the patients classified into 3 study groups: (1) survival study group; (2) tissue microarray (TMA) study group; and (3) primary culture study group.

\section{Tissue Samples, Tissue Microarray and Immunohistochemistry (IHC)}

The surgical specimens were fixed in formalin and embedded in paraffin (FFPE). Tissue sections were stained with hematoxylin and eosin (H\&E) for histopathological examination.

Fifty-five women with cervical cancer who underwent radical hysterectomy in 2000-2002 were chosen into the survival study group. All cases had previously been analyzed for HPV genotypes.

In addition, 58 cervical cases were enrolled between 2004 and 2012 into the TMA study group. Representative normal and tumorous areas were selected for the construction of TMAs, which contained $2 \mathrm{~mm}$ cores in diameter of each case.

Syndecan-1 (clone BB4) staining of the survival study group and its evaluation were followed as previously reported [32]. Briefly, independent observers manually scored membrane syndecan-1 based on intensity levels ranging from 0 to $2+$ and absence or presence of stromal syndecan-1 in tumor areas twice. As later on BB4 clone was not available anymore, syndecan-1 expression was tested on still available sections with the clone MI15, as well.

Syndecan-1 (clone MI15) and vimentin immunostainings of TMAs were carried out using a Leica BOND-MAX ${ }^{\mathrm{TM}}$ autostainer (Leica GmbH, Nussloch, Germany), according to the manufacturer's instructions [34]. Primary and secondary antibodies are listed in Table 2. Syndecan-1 (clone MI15) and vimentin primary antibodies are used in routine diagnostic use. 
Table 1 Clinical data of study groups

\begin{tabular}{|c|c|c|c|c|c|c|}
\hline & \multicolumn{2}{|c|}{ Survival study } & \multicolumn{2}{|c|}{ TMA study } & \multicolumn{2}{|c|}{ Primary culture study } \\
\hline Number of cases & 55 & & 58 & & 17 & \\
\hline Median age (years) & $47(25-7$ & & $45(31-7$ & & $51(36-7 c$ & \\
\hline Histology & Number & $\%$ & Number & $\%$ & Number & $\%$ \\
\hline Adenosquamous carcinoma & 1 & 1.8 & 5 & 8.6 & 1 & 5.9 \\
\hline Adenocarcinoma & 0 & 0.0 & 7 & 12.1 & 1 & 5.9 \\
\hline Squamous cell carcinoma & 54 & 98.2 & 43 & 74.1 & 15 & 88.2 \\
\hline Dysplasia & 0 & 0.0 & 1 & 1.7 & 0 & 0.0 \\
\hline No tumor & 0 & 0.0 & 2 & 3.4 & 0 & 0.0 \\
\hline \multicolumn{7}{|l|}{ FIGO Stage } \\
\hline IA & 2 & 3.6 & 1 & 1.7 & - & - \\
\hline IB & 15 & 27.3 & 16 & 27.6 & 1 & 5.9 \\
\hline IIA & 12 & 21.8 & 10 & 17.2 & 1 & 5.9 \\
\hline IIB & 23 & 41.8 & 14 & 24.1 & - & - \\
\hline IIIB & 3 & 5.5 & - & - & - & - \\
\hline No data & 0 & 0.0 & 17 & 29.3 & 15 & 88.2 \\
\hline \multicolumn{7}{|l|}{ Grade } \\
\hline 1 & 19 & 34.5 & 13 & 22.4 & - & - \\
\hline 2 & 30 & 54.5 & 23 & 39.7 & - & - \\
\hline 3 & 6 & 10.9 & 2 & 3.4 & - & - \\
\hline No data & 0 & 0.0 & 20 & 34.5 & 17 & 100.0 \\
\hline Metastasis & 22 & 40.0 & 27 & 46.6 & 7 & 41.2 \\
\hline \multicolumn{7}{|l|}{ HPV status } \\
\hline Only HPV16 & 27 & 49.1 & 17 & 29.3 & - & - \\
\hline Only HPV18 & 2 & 3.6 & 2 & 3.4 & - & - \\
\hline Only HPV33 & 0 & 0.0 & 0 & 0.0 & - & - \\
\hline HPV16 + 18 & 12 & 21.8 & 5 & 8.6 & - & - \\
\hline HPV16 + 33 & 7 & 12.7 & 1 & 1.7 & - & - \\
\hline HPV18 + 33 & 1 & 1.8 & 0 & 0.0 & - & - \\
\hline HPV16 + $18+33$ & 5 & 9.1 & 3 & 5.2 & - & - \\
\hline HPV negative & 1 & 1.8 & 8 & 13.8 & - & - \\
\hline No data & 0 & 0.0 & 22 & 37.9 & 17 & 100.0 \\
\hline No survival data & 4 & 7.3 & - & - & - & - \\
\hline
\end{tabular}

Type-specific determination of HPVs was carried out by nested PCR as described previously [35].

\section{Raw Materials}

The raw materials and devices used in cell culture were from Sigma-Aldrich Co. (St. Louis, MO, USA) and SARSTEDT AG\&Co (Nümbrecht, Germany). Reagents used in the experiments were purchased from Sigma-Aldrich Co. and Merck (Darmstadt, F. R. Germany).

\section{Generation of Primary Cell Cultures}

Fibroblasts from normal (NF) and tumorous (CAF) regions of uterine cervix not used for diagnosis were obtained from explant cultures. These surgical specimens 
Table 2 Antibodies used

\begin{tabular}{|c|c|c|c|c|c|}
\hline Antibody & & Host species, isotype & Manufacturer* & Cat. No. & $\begin{array}{l}\text { Dilution } \mathrm{IHC} / \\
\mathrm{IF}\end{array}$ \\
\hline \multirow[t]{8}{*}{ Primary } & Vimentin & Mouse monoclonal IgG, clone V9 & Dako & M0725 & $1: 300$ \\
\hline & Cytokeratin & $\begin{array}{l}\text { Mouse monoclonal IgG, clone } \\
\text { AE1/AE3 }\end{array}$ & Dako & M3515 & $1: 100$ \\
\hline & Smooth Muscle Actin (SMA) & Mouse monoclonal IgG, clone $1 \mathrm{~A} 4$ & Dako & M0851 & $1: 200$ \\
\hline & Desmin & Mouse monoclonal IgG, clone D33 & Dako & M0760 & $1: 100$ \\
\hline & Syndecan-1 (sdc1) & Mouse monoclonal IgG, clone MI15 & Dako & M7228 & $1: 100$ \\
\hline & Syndecan-1 (sdc1) & Mouse monoclonal IgG, clone B-B4 & AbD Serotec & MCA681F & $1: 500$ \\
\hline & Pan cytokeratin FITC labeled & Mouse monoclonal IgG, clone LP34 & Dako & F0859 & $1: 100$ \\
\hline & CD138 Alexa Fluor® 647 labeled & Mouse monoclonal IgG, clone B-B4 & AbD Serotec & MCA681A647 & $1: 100$ \\
\hline \multirow[t]{4}{*}{ Secondary } & Anti-mouse IgG/Biotin & Goat polyclonal & DakoCytomation & E0433 & $1: 200$ \\
\hline & Alexa Fluor ${ }^{\circledR} 568$ anti-mouse $\operatorname{IgG}(\mathrm{H}+\mathrm{L})$ & Donkey polyclonal & Invitrogen & 43497A & $1: 200$ \\
\hline & Alexa Fluor ${ }^{\circledR} 488$ anti-mouse $\operatorname{IgG}(\mathrm{H}+\mathrm{L})$ & Donkey polyclonal & Invitrogen & A21202 & $1: 200$ \\
\hline & Anti-Mouse IgG TRITC & Goat polyclonal & Sigma-Aldrich & T5393 & $1: 100$ \\
\hline
\end{tabular}

IHC: immunohistochemistry, IF: fluorescent cytochemistry

*Dako/DakoCytomation, Agilent Technologies, Inc., Santa Clara, CA. USA; Invitrogen by Life Technologies. Carlsbad. CA. USA; Sigma-Aldrich/ Merck, St. Louis, MO, USA; AbD Serotec, Kidlington, UK

were excised and cut into small pieces and placed into six-well tissue culture dishes containing AmnioGrow Plus medium (CytoGen GmbH, Sinn, Germany), optimized for development of primary cell culture. After the third passage, growing fibroblasts were routinely transferred into DMEM-low glucose medium supplemented with $10 \%$ fetal bovine serum (FBS), $2 \mathrm{mM}$ L-glutamine, $100 \mathrm{unit} / \mathrm{mL}$ penicillin and $100 \mu \mathrm{g} / \mathrm{mL}$ streptomycin. Purity of the fibroblast cultures was tested by vimentin and cytokeratin fluorescent immunostaining. We established 22 primary cervical cultures $(7 \mathrm{NFs}+15$ CAFs) from 17 patients for immunocytochemistry examinations (Table 1, primary culture study group). Primary cultures were used for research until 10th passage. Fibroblasts were vimentin positive and pan-cytokeratin negative cells displaying spindle-like morphology, with elongated, oval nuclei.

HPV16-positive CSCC1 (cervical squamous cell carcinoma 1) cervical cancer cell line, derived from a case of squamous cervical cancer, was a kind gift from A. Gorter (Leiden University, Leiden, the Netherlands) [36]. These cells exhibit a clear epithelial morphology and form nests when grown in monoculture. They express pancytokeratin but lack vimentin. CSCC1 cells were routinely cultured in RPMI-1640 medium supplemented with $10 \%$ FBS, $2 \mathrm{mM}$ L-glutamine, $1 \mathrm{mM}$ sodium pyruvate, $100 \mathrm{unit} / \mathrm{mL}$ penicillin and $100 \mu \mathrm{g} / \mathrm{mL}$ streptomycin. All cell lines and primary cells were cultured in a humidified $95 \%$ air $/ 5 \% \mathrm{CO}_{2}$ incubator at $37{ }^{\circ} \mathrm{C}$.
Fibroblasts were cultured either as monocultures or direct co-cultures with CSCC1.

\section{Direct Co-culture System}

Direct co-culturing allowed physical interaction between fibroblasts and tumor cells. Accordingly, NF and CSCC1 cells were seeded alone $\left(5 \times 10^{5}\right.$ cells/culture dish density) or in the same culture dish together $\left(\mathrm{NF}+\mathrm{CSCC} 1 ; 5 \times 10^{5}-5 \times 10^{5}\right.$ cells/culture dish density) in a 1:1 (v/v) mixture of DMEM-low glucose and RPMI-1640 supplemented with 10\% FBS, 2 mM L-glutamine, $100 \mathrm{unit} / \mathrm{mL}$ penicillin and $100 \mu \mathrm{g} / \mathrm{mL}$ streptomycin.

\section{Immunocytochemistry}

Forty-eight hours after seeding cells from monoculture and direct co-culture model systems grown on coverslips were captured using Olympus CK2 inverted phase microscope equipped with an Olympus DP50 CCD camera (Olympus Corporation, Tokyo, Japan). Then immunofluorescence staining was performed on methanol-acetone-fixed glass coverslips according to standard protocols [37]. In case of multiple labeled fluorescent staining, vimentin or desmin was labelled with TRITC, then pan cytokeratin conjugated to FITC and Alexa Fluor ${ }^{\circledR} 647$ labeled syndecan-1 were used. Primary and secondary antibodies are detailed in Table 2 . Nuclei were stained with $1 \mu \mathrm{g} / \mathrm{mL}$ DAPI in PBS for 5 min except by triplecolor staining. Photographs were taken with a Nikon Eclipse E600 microscope (Nikon Corporation, Tokyo, Japan) operated by the Lucia Cytogenetics version 1.5.6 program 
(Laboratory Imaging, Praha, Czech Republic) or MRC-1024 confocal laser scanning microscope (Bio-Rad Laboratories GmbH, Munich, Germany).

\section{Statistical Analysis}

Data were analyzed using Microsoft Excel v.2016 (Microsoft Corp., Redmond, WA, USA) and GraphPad Prism 8 (GraphPad Software, La Jolla, ca., USA). The expression differences between normal cervix and cervix carcinoma in case of TMAs were analyzed by nonparametric Mann-Whitney test. Correlation analysis between IHC scores and clinicopathologic data of patients were performed with a nonparametric Spearman rank-order correlation test. Survival curves were analyzed using the Kaplan-Meier method and differences between survival curves of different groups were defined by the log-rank test. A $p$ value of 0.05 was set as the threshold for statistical significance.

\section{Results}

\section{Expression of Cell Surface Syndecan-1 is Related to Survival}

A decrease in cell surface syndecan-1 (sdc1) expression was detectable in the majority of the tumors examined. No membrane reaction comparable in intensity with normal epithelial cells was detected. A moderately decreased reactivity $(2+)$ was recorded in $13 / 55$, a strongly decreased (1+) in $20 / 55$ and no reaction ( 0 ) in 22/55 cases. The metastases present in the lymph nodes also showed decreased syndecan-1 membrane positivity as well.

Similar to earlier studies, the degree of reduction of membrane syndecan- 1 expression followed the histological grade, i.e. more differentiated tumors expressed more syndecan-1 (Spearman correlation: $p=0.0055, \mathrm{r}=-0.3696$ ). Loss of membranous syndecan-1 expression associated with higher mortality rate when the postoperative survival time was elongated (51/55) (Fig. 1a). The 5, 10 and 15-year overall survivals were $64.7 \%$ (log rank test: $p=0.0374), 60.8 \%$ (log rank test: $p=$ $0.1721)$ and $49 \%$ (log rank test: $p=0.3663)$. The promotion of survival was significant until the seventh year.

\section{Effect of Stromal Syndecan-1 Expression On Survival}

In 26/55 (47\%) cervical tumors, abnormal syndecan-1 localization was found in the stroma, most probably due to aberrant expression of this proteoglycan by stromal fibroblasts. Moreover, the lymph node metastases of these tumors preserved their inductive potential on stromal cells, as fibroblasts detected in metastases were also positive for syndecan-1. It was observed that the more of the syndecan- 1 was localized in the stroma, the less of it was found on the cancer cells.
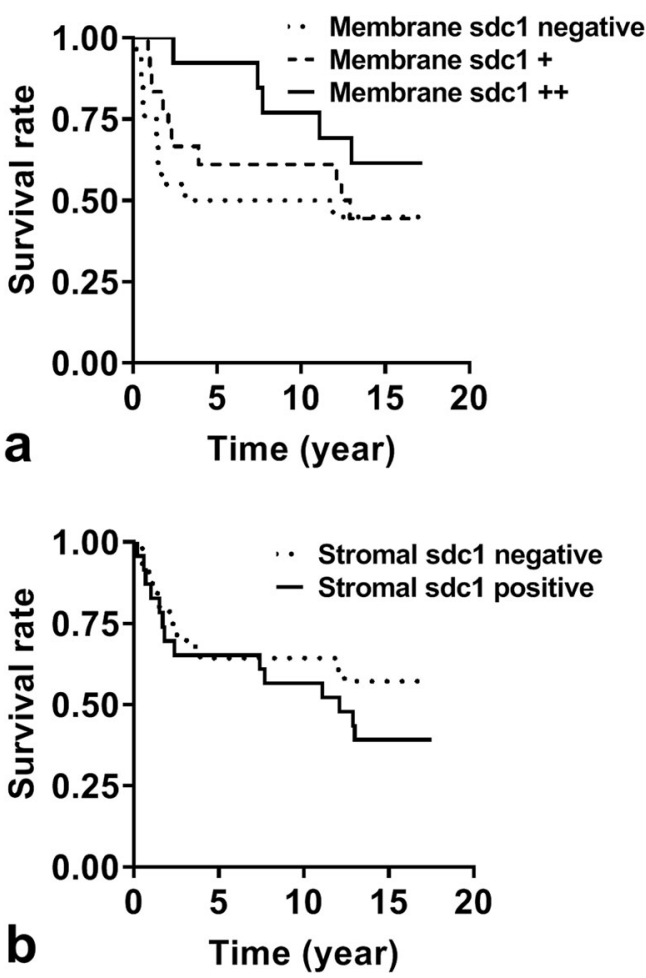

Fig. 1 Cell surface syndecan-1 expression provides survival benefit for seven years . Kaplan-Meier 15-year survival curves of patients with cervical cancer grouped by the presence or absence of membrane (a) and stromal (b) syndecan-1 (survival study group). Sdc1: syndecan-1

However, although it seems likely that aberrant expression of syndecan-1 favors tumor progression, analysis of 51/55 patients in the survival study group revealed lack of significance between stromal syndecan-1 expression and survival (log rank test: $p=0.2765$; Fig. $1 \mathrm{~b}$ ).

\section{Variations of Syndecan-1 and Vimentin Expression in Cervical Cancer}

Immunostaining of TMA allowed the simultaneous examination of peritumoral, seemingly normal and tumorous cervix in 58 cases. In addition to syndecan-1, the expression of vimentin was also detected. Stromal cells of tumorous area contained more vimentin than those from non-tumorous regions (1.6-fold, Mann-Whitney test: $p<0.0001)$ (Fig. 2d-f,j). Moreover, indicating epithelial-mesenchymal transition (EMT), vimentin occurred in the cytoplasm of several tumor cells (Fig. 2e). Syndecan-1 expression of normal squamous epithelial cells showed similar trends to those of the survival study group (Fig. 2g). Similarly to the survival study, syndecan-1 intensity of tumorous membrane decreased and its presence in the interstitial stroma could be detected (Fig. $2 \mathrm{~h}, \mathrm{i})$. The intensity of stromal syndecan-1 immunostaining was 7.3-fold higher (Mann Whitney test: $p<0.0001$ ) in cervical cancer than in normal tissues (Fig. 2j). Few samples from 

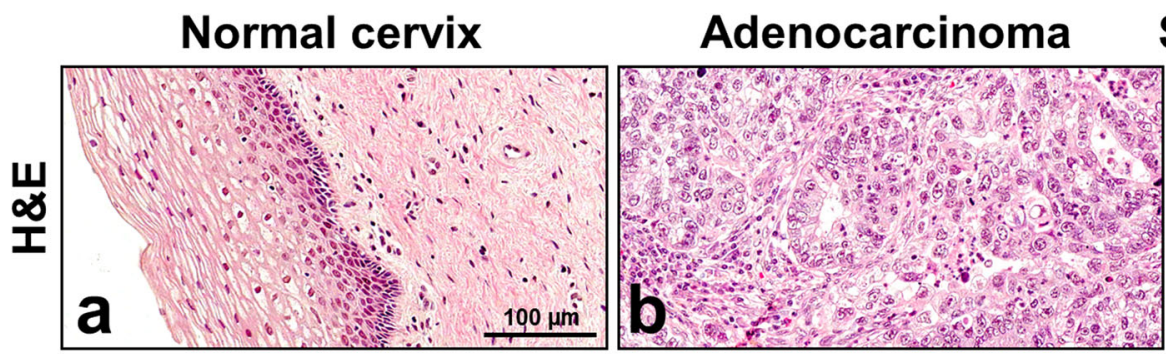

Squamous cell carcinoma
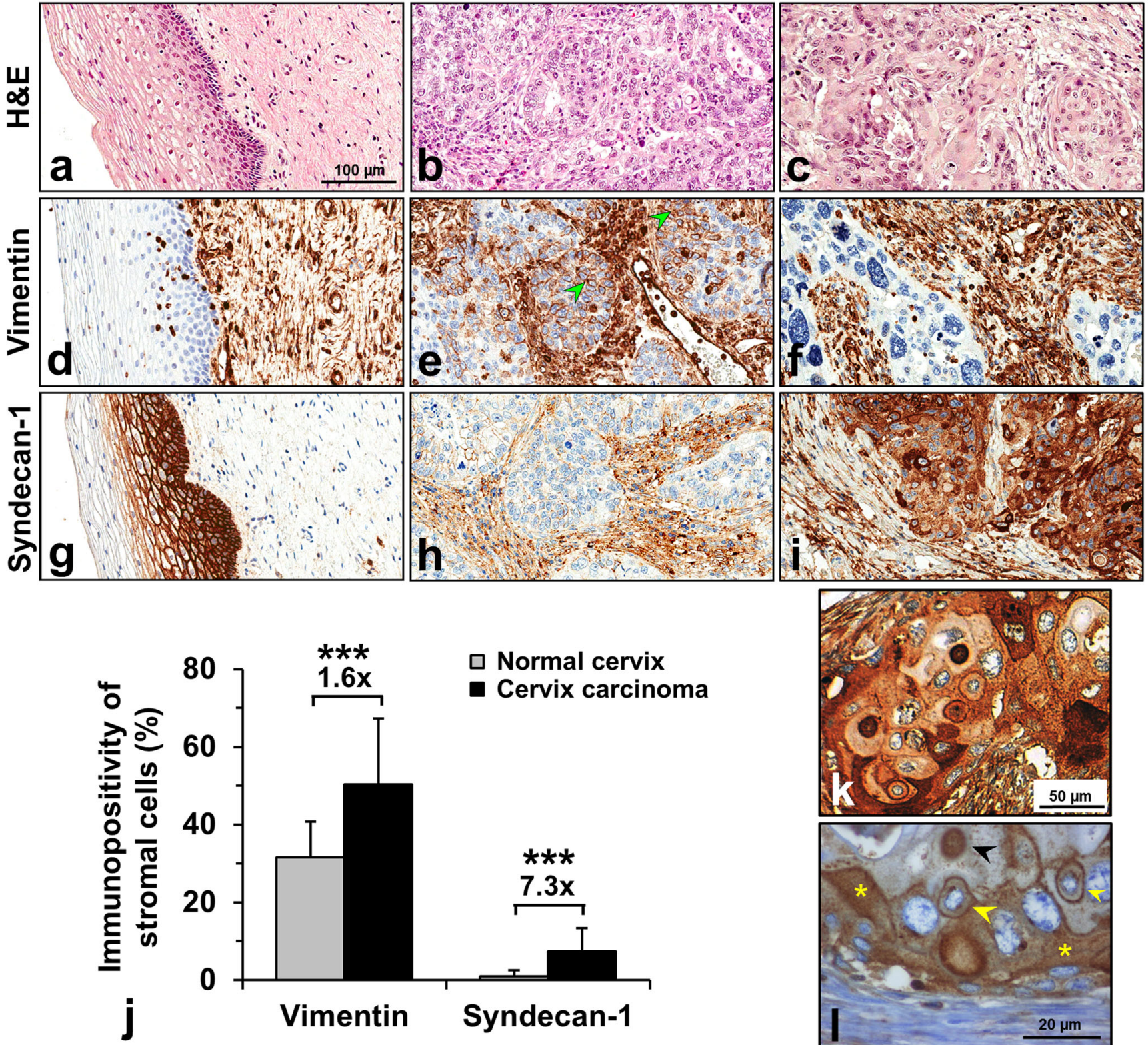

Fig. 2 Expression of vimentin and syndecan-1 in normal cervix and cervical cancer. H\&E staining of normal cervix, adenocarcinoma and squamous cells of the cervix (a-c) (TMA study group). Vimentin was present as homogenous staining in the connective tissue of normal cervix (d), the reaction is distributed in the tumorous stroma in a similar manner (e,f). In addition, cytoplasmic vimentin positivity can be detected both in adenocarcinoma (green arrows) (e) and squamous cell carcinoma (data not shown). Strong membranous syndecan-1 reaction is detectable in normal cervical epithelium (g), whereas aberrant stromal syndecan-1 positivity appears in cervical cancer $(\mathbf{h}, \mathbf{i})$. Densitometric evaluation showed that both vimentin and syndecan-1 immunostainings were significantly increased in the stromal compartment of cervical cancer tissues (black

column) compared to normal tissues (gray column). The signal positivity of stromal cells is shown as a proportion of the total measured area (j). Specificity of immunoreaction of both syndecan-1 antibodies on the same squamous cell carcinoma sample of survival study group presented on $\mathbf{k}$ (clone MI15) and I (clone BB4). Cell surface syndecan-1 seems to translocate to the nucleus (black arrow), the perinuclear membrane (yellow arrow) and the cytoplasm (yellow star) abnormally (k). Representative images of same TMA cores (a-i) or sample (k,l), hematoxylin counterstain, 100x magnifications with scale bar $100 \mu \mathrm{m}$ (a-i); 200x magnifications with scale bar $50 \mu \mathrm{m}(\mathbf{k}) ; 400 \mathrm{x}$ magnification with scale bar $20 \mu \mathrm{m}$ (l), stars indicate significance: $* * * p<0.001$

survival study group were stained by both syndecan- 1 antibodies showing the same localization on the same samples (Fig. 2k,1). Furthermore, Fig. 2i,k and 1 are good examples for altered localization of syndecan-1 in cancer cells showing the proteoglycan in the cytoplasm, infrequently in the nucleus and the perinuclear membrane of cancer cells. 


\section{Characteristics of Normal and Tumorous Fibroblasts in Tissue Cultures}

Seven NF and 15 CAF cervical primary cultures have been established, containing $3 \mathrm{NF}-\mathrm{CAF}$ matched primary culture pairs derived from the same 3 patients.

All of 22 fibroblast primary cultures showed the presence of vimentin and desmin. From those, 17 expressed SMA in various amounts indicating that these cells are activated myofibroblasts (Fig. 3a). Syndecan-1 was detected in 14 primary cultures most of them being CAFs (13/15). In case of NF-CAF matched pairs, all NFs were negative, and all CAFs expressed syndecan-1.

In addition to cytoplasmic desmin/vimentin, few cells from 6 CAF primary cultures also expressed cytokeratin (6/15) presenting EMT of tumor cells (Fig. 3b,c). Three of them also expressed syndecan-1 in less than 3\% of cytokeratin positive cells as we published earlier [38]. In co-culture the presence of NFs stimulated the proliferation of CSCC1 cells compared to their monoculture (Fig. 3d).

Co-cultivation of NFs with CSCC1 cells induced syndecan-1 expression in previously syndecan-1-negative fibroblasts (Fig. 4).

\section{Discussion}

Previous studies on the role of syndecan-1 in tumors mainly focused on the changes of this HSPG taking place on the surface of tumor cells. In support of earlier reports, we observed serious abnormalities in the expression of syndecan-1 in invasive cervical cancers. In comparison with the normal epithelium, tumor cell membrane syndecan-1 immunoreaction was moderately or strongly decreased in the majority of the cases; moreover, its occasional disappearance was also observed. Higher syndecan1 expression was accompanied with significantly better survival until the 7th year indicating that it can be considered as a prognostic marker. Statistical significance was lost in the following 8 years, presumably due to decreased number of cases. This is in an agreement with long-term survival study of Numa et al. [24]. We attempted to utilize the TMA group for survival analysis to increase the number of cases of survival study, however it seems that the small areas present in the TMA are not representative enough to gain reliable results. Henceforward, using the TMA platform and the computed analysis we compared the stromal syndecan-1 and vimentin expression on normal and tumorous areas.

In recent years, increasing interest has been directed towards the ectopic stromal expression of syndecan-1. Increasing evidence indicates that human tumor cells are capable of inducing stromal syndecan-1 expression which represents a distinct subgroup with worse life expectancy [21, 28]. In our study syndecan-1 immunoreaction was noticeable in vimentinpositive mesenchymal cells, identifying these cells as the source of stromal syndecan-1. Aberrant, tumor-induced stromal expression of syndecan-1 both in squamous cell and adenocarcinomas, as recorded in our specimens, is a novel finding in cervical cancer. Also, to confirm the specificity of this abnormal expression we used two syndecan- 1 antibodies receiving the same abnormal

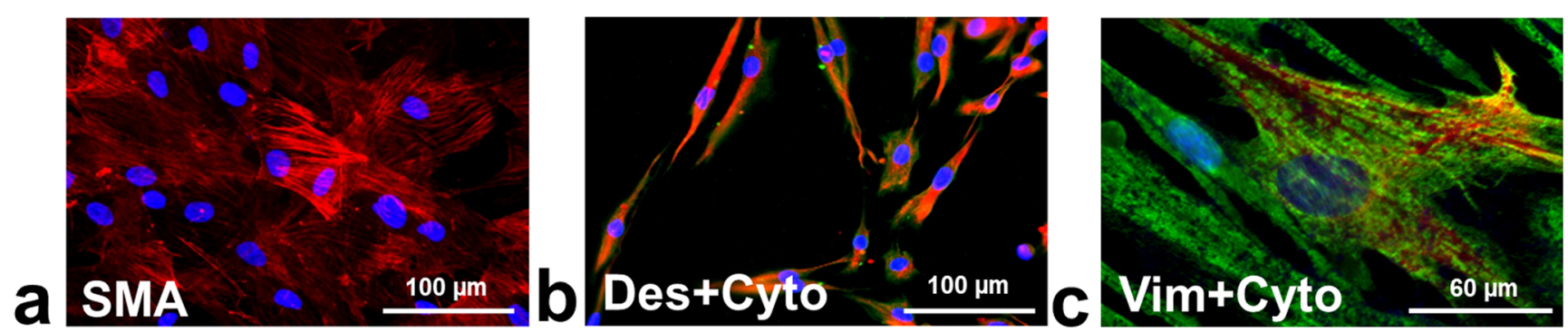

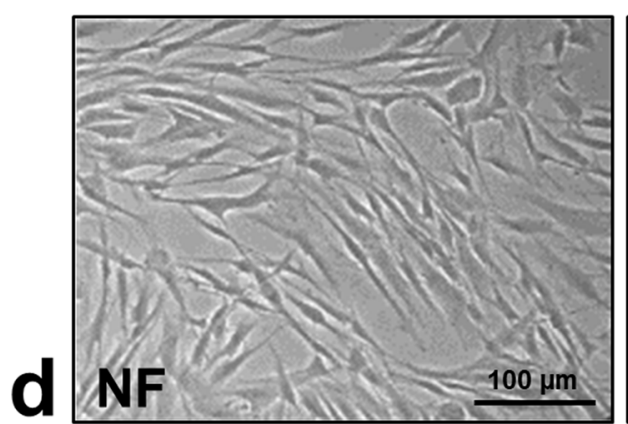

Fig. 3 Fibroblasts and their effect on the proliferation of CSCC1 cells. Most of the fibroblast primary cultures expressed SMA (a). Some cells showing fibroblast morphology with desmin positivity (red) also expressed epithelial marker cytokeratin (green) (b) or with vimentin positivity (green) and cytokeratin positivity (red) (c). Nuclei were stained
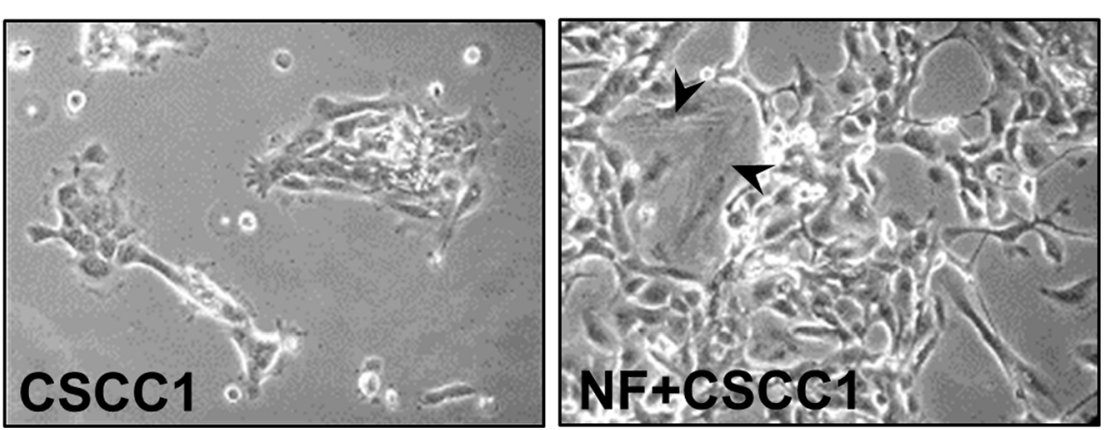

with DAPI. CSCC1 cells grew much faster in the presence of NFs (black arrow) than alone $48 \mathrm{~h}$ after seeding; equal number of cells were seeded (d); 200x magnifications with scale bar $100 \mu \mathrm{m}, 600 \mathrm{x}$ magnifications with scale bar $60 \mu \mathrm{m}$ 
Fig. 4 Tumor-induced aberrant syndecan-1 positivity of cervical fibroblasts. In monoculture the presented NFs were syndecan-1 negative, however in direct coculture with syndecan-1-positive CSCC1, NFs also expressed syndecan-1 (blue, $\mathbf{c}$ ) in addition to fibroblast marker vimentin (red, a). $\mathrm{CSCC} 1$ showed presence of the epithelial marker cytokeratin (green, b) and the lack thereof for vimentin. Merged image of triplecolor immunofluorescence (d); 200x magnifications, scale bar $100 \mu \mathrm{m}$
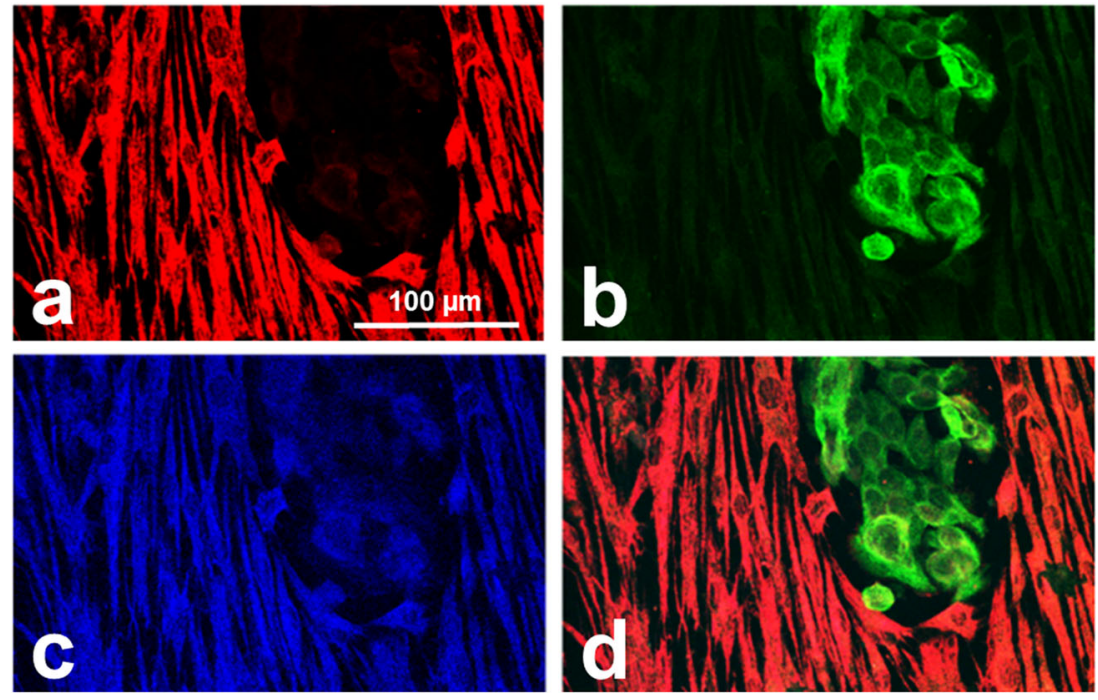

expression. The stromal syndecan-1 expression was regularly seen in combination with the reduced membranous syndecan1 positivity of the tumor cells. In spite of that, we failed to confirm significant relationship between stromal syndecan-1 expression and patient survival.

A rather general observation is that in the complex relationship between the stroma and the tumor cells syndecan-1 acts as a mediator of reciprocal interactions [33]. The heparan sulfate glycosaminoglycan chains of this proteoglycan intensively influence the quantity and localization of growth factors and cytokines in the tumor microenvironment. An excess of growth factors, bound by heparan sulfate chains of syndecan1, abnormally expressed on the surface of stromal cells may lead to aggressive clinical tumor phenotype. This hypothesis has been supported by in vitro studies, in which ductal mammary tumor cells and fibroblasts were co-cultured [33]. Further support comes from a relevant in vivo study [39]. Our previous work demonstrated that remodeling of ECM by fibroblasts promotes cervical cancer progression [38]. Now, our culture models confirmed that syndecan-1 expression by stromal cells is a typical feature of fibroblasts isolated from cervical cancers. Most of the CAFs presented syndecan1 positivity in monoculture. Furthermore, their direct contact with cancer cells induced the production of syndecan- 1 in normal fibroblasts that lacked syndecan-1 expression in monoculture. Syndecan-1-expressing fibroblasts reorganize the ECM promoting adhesion and directional movements of tumor cells during migration [40]. As even NFs started to express syndecan-1 in direct co-culture indicates that tumor cells are responsible for the induction of this proteoglycan. Higher syndecan-1 levels, in turn, accelerate the proliferation of the tumor cells, thus constituting a positive feedback loop $[41,42]$.

The question has to be addressed if syndecan-1 expression promotes the aggressive phenotype of EMT transformed tumor cells present in the stroma. We determined the proportion of vimentin-syndecan-1-cytokeratin positive cells in our primary fibroblast cultures. Among those six contained cytokeratin positive cells but they were syndecan- 1 negative in 3 cultures. The proportion of cells with cytokeratin/syndecan-1 positivity was below $3 \%$ in the remaining three cases. This result indicates, that syndecan-1 does not enhance the aggressive phenotype of EMT transformed tumor cells of cervix, which can be accomplished by the classical markers of EMT.

In addition to epithelial-mesenchymal switch, other abnormalities also can be found in cervical cancers. Impaired secretion of the proteoglycan results in cytoplasmic localization, and syndecan-1 presence can be detected in the cell nuclei as well. These findings are supported by multiple studies investigating other types of cancer [43-46]. Kim et al. scoring the cytoplasmic syndecan-1 in cervical cancer found that strong syndecan-1 expression is associated with better survival [47]. Changing syndecan-1 localization from surface to cytoplasm in cancers leads to lose its original function, connecting the cell to ECM. This allows increased mobility, thus, gaining invasive and metastatic properties and increasing the number of fibroblast-like cells in the tumor microenvironment. Certainly, in our tissue culture model, double vimentin-cytokeratin immunostaining demonstrated this mesenchymal transition of tumor cells.

\section{Conclusions}

Independent of the ultimate clinical outcome, our immunohistochemical and immunocytochemical observations confirmed that tumor-induced stromal syndecan-1 expression is a common event in human carcinomas, including cervical cancers. Although, in vitro studies demonstrated that proliferation of cancer cells is stimulated by stromal syndecan-1, we failed to 
prove its negative effects in vivo, most likely due to the involvement of additional regulatory factors.

Acknowledgements The authors thank Krisztina Egedi and László Ötvös (Semmelweis University) for their assistance.

Author Contributions KK: conceived and designed and completed the experiments, analyzed the data and contributed to drafting of the manuscript. RV, MM, AF, LO and TF: conceived the study, participated in its design and coordination, performed the statistical analysis. ZP: carried out the surgeries and collected the samples. IK: conceived the study, participated in the design and coordination, and assembled the report. All authors read and approved the final manuscript.

Funding Information Open access funding provided by Semmelweis University (SE). This work was supported in part by the Hungarian Scientific Research Fund, grants \#67925, \#100904 and \#119283 (to IK), by the EFOP-3.6.3-VEKOP-16-2017-00009 (HRDOP-3.6.3-CCHOP-16: Human ResourcesDevelopment Operational Program, Competitive Central Hungary Operational Program) "Development of theScientific Workshops of Medical, Health Science and Pharmacist Education" pre-doctoral fellowship, cofinancedby the European Union and the European Social Fund (to KK) and European Union Horizon 2020 Marie Skłodowska-Curie Actions (MSCA) Research and Innovation Staff Exchange Evaluations (RISE) project\#645756 GLYCANC - Matrix glycans as multifactional pathogenesis factors and therapeutic targets in cancer (to IK).

Data Availability All data generated or analyzed during this study are included in this published article.

\section{Compliance with Ethical Standards}

Conflicts of Interest The authors declare that they have no conflict of interest.

Ethics Approval The surgical materials were collected and used according to the instructions of Semmelweis University Regional and Institutional Committee of Science and Research Ethics (TUKEB permit number: 95/1999). Specimens and data were stored anonymously.

Consent to Participate Informed consent was obtained from all individual participants included in the study.

Consent for Publication Additional informed consent was obtained from all individual participants for whom identifying information is included in this article.

Code Availability Not applicable.

Open Access This article is licensed under a Creative Commons Attribution 4.0 International License, which permits use, sharing, adaptation, distribution and reproduction in any medium or format, as long as you give appropriate credit to the original author(s) and the source, provide a link to the Creative Commons licence, and indicate if changes were made. The images or other third party material in this article are included in the article's Creative Commons licence, unless indicated otherwise in a credit line to the material. If material is not included in the article's Creative Commons licence and your intended use is not permitted by statutory regulation or exceeds the permitted use, you will need to obtain permission directly from the copyright holder. To view a copy of this licence, visit http://creativecommons.org/licenses/by/4.0/.

\section{References}

1. Bray F, Ferlay J, Soerjomataram I, Siegel RL, Torre LA, Jemal A (2018) Global cancer statistics 2018: GLOBOCAN estimates of incidence and mortality worldwide for 36 cancers in 185 countries. Cancer J Clin 68(6):394-424. https://doi.org/10.3322/caac.21492

2. LaVigne AW, Triedman SA, Randall TC, Trimble EL, Viswanathan AN (2017) Cervical cancer in low and middle income countries: Addressing barriers to radiotherapy delivery. Gynecol Oncol Rep 22:16-20. https://doi.org/10.1016/j.gore.2017.08.004

3. Witsch E, Sela M, Yarden Y (2010) Roles for growth factors in cancer progression. Physiology (Bethesda Md) 25(2):85-101. https://doi.org/10.1152/physiol.00045.2009

4. Erdogan B, Webb DJ (2017) Cancer-associated fibroblasts modulate growth factor signaling and extracellular matrix remodeling to regulate tumor metastasis. Biochem Soc Trans 45(1):229-236. https://doi.org/10.1042/bst20160387

5. Liotta LA (1986) Tumor invasion and metastases-role of the extracellular matrix: Rhoads Memorial Award lecture. Cancer Res 46(1):1-7

6. Liotta LA (2016) Adhere, degrade, and move: the three-step model of invasion. Cancer Res 76(11):3115-3117. https://doi.org/10. 1158/0008-5472.Can-16-1297

7. Bernfield M, Kokenyesi R, Kato M, Hinkes MT, Spring J, Gallo RL, Lose EJ (1992) Biology of the syndecans: a family of transmembrane heparan sulfate proteoglycans. Annu Rev Cell Biol 8: 365-393. https://doi.org/10.1146/annurev.cb.08.110192.002053

8. Kovalszky I, Nagy P, Szende B, Lapis K, Szalay F, Jeney A, Schaff Z (1998) Experimental and human liver fibrogenesis. Scand J Gastroenterol Suppl 228:51-55

9. Rapraeger AC (2000) Syndecan-regulated receptor signaling. J Cell Biol 149(5):995-998. https://doi.org/10.1083/jcb.149.5.995

10. Woods A, Couchman JR (1998) Syndecans: synergistic activators of cell adhesion. Trends Cell Biol 8(5):189-192

11. Beauvais DM, Rapraeger AC (2003) Syndecan-1-mediated cell spreading requires signaling by alphavbeta3 integrins in human breast carcinoma cells. Exp Cell Res 286(2):219-232. https://doi. org/10.1016/s0014-4827(03)00126-5

12. Dobra K, Nurminen M, Hjerpe A (2003) Growth factors regulate the expression profile of their syndecan co-receptors and the differentiation of mesothelioma cells. Anticancer Res 23(3b):2435-2444

13. Jayson GC, Vives C, Paraskeva C, Schofield K, Coutts J, Fleetwood A, Gallagher JT (1999) Coordinated modulation of the fibroblast growth factor dual receptor mechanism during transformation from human colon adenoma to carcinoma. Int $\mathrm{J}$ Cancer 82(2):298-304

14. Larrain J, Carey DJ, Brandan E (1998) Syndecan-1 expression inhibits myoblast differentiation through a basic fibroblast growth factor-dependent mechanism. J Biol Chem 273(48):32288-32296. https://doi.org/10.1074/jbc.273.48.32288

15. Mundhenke C, Meyer K, Drew S, Friedl A (2002) Heparan sulfate proteoglycans as regulators of fibroblast growth factor-2 receptor binding in breast carcinomas. Am J Pathol 160(1):185-194. https:// doi.org/10.1016/s0002-9440(10)64362-3

16. Soukka T, Pohjola J, Inki P, Happonen RP (2000) Reduction of syndecan-1 expression is associated with dysplastic oral epithelium. J Oral Pathol Med 29(7):308-313

17. Timar J, Lapis K, Dudas J, Sebestyen A, Kopper L, Kovalszky I (2002) Proteoglycans and tumor progression: Janus-faced molecules with contradictory functions in cancer. Sem Cancer Biol 12(3):173-186. https://doi.org/10.1016/s1044-579x(02)00021-4

18. Sobel G, Szabo I, Paska C, Kiss A, Kovalszky I, Kadar A, Paulin F, Schaff Z (2005) Changes of cell adhesion and extracellular matrix (ECM) components in cervical intraepithelial neoplasia. Pathol Oncol Res 11(1):26-31 
19. Kurokawa H, Matsumoto S, Murata T, Yamashita Y, Tomoyose T, Zhang M, Fukuyama H, Takahashi T (2003) Immunohistochemical study of syndecan-1 down-regulation and the expression of p53 protein or Ki-67 antigen in oral leukoplakia with or without epithelial dysplasia. J Oral Pathol Med 32(9):513-521

20. Inki P, Stenback F, Grenman S, Jalkanen M (1994) Immunohistochemical localization of syndecan-1 in normal and pathological human uterine cervix. J Pathol 172(4):349-355. https://oi.org/10.1002/path.1711720410

21. Wiksten JP, Lundin J, Nordling S, Lundin M, Kokkola A, von Boguslawski K, Haglund C (2001) Epithelial and stromal syndecan-1 expression as predictor of outcome in patients with gastric cancer. Int J Cancer 95(1):1-6

22. Rintala M, Inki P, Klemi P, Jalkanen M, Grenman S (1999) Association of syndecan-1 with tumor grade and histology in primary invasive cervical carcinoma. Gynecol Oncol 75(3):372-378. doi:https://doi.org/10.1006/gyno.1999.5595

23. Nakanishi K, Yoshioka N, Oka K, Hakura A (1999) Reduction of syndecan-1 mRNA in cervical-carcinoma cells is involved with the 3' untranslated region. Int J Cancer 80(4):527-532

24. Numa F, Hirabayashi K, Kawasaki K, Sakaguchi Y, Sugino N, Suehiro Y, Suminami Y, Hirakawa H, Umayahara K, Nawata S, Ogata H, Kato H (2002) Syndecan-1 expression in cancer of the uterine cervix: association with lymph node metastasis. Int J Oncol 20(1):39-43

25. Kopper L, Sebestyen A (2000) Syndecans and the lymphoid system. Leuk Lymphoma 38(3-4):271-281. https://doi.org/10.3109/ 10428190009087018

26. Larrain J, Cizmeci-Smith G, Troncoso V, Stahl RC, Carey DJ, Brandan E (1997) Syndecan-1 expression is down-regulated during myoblast terminal differentiation. Modulation by growth factors and retinoic acid. J Biol Chem 272(29):18418-18424. https://doi. org/10.1074/jbc.272.29.18418

27. Mennerich D, Vogel A, Klaman I, Dahl E, Lichtner RB, Rosenthal A, Pohlenz HD, Thierauch KH, Sommer A (2004) Shift of syndecan-1 expression from epithelial to stromal cells during progression of solid tumours. Eur J Cancer (Oxford, England: 1990) 40(9):1373-1382. https://doi.org/10.1016/j.ejca.2004.01.038

28. Stanley MJ, Stanley MW, Sanderson RD, Zera R (1999) Syndecan1 expression is induced in the stroma of infiltrating breast carcinoma. Am J Clin Pathol 112(3):377-383. https://doi.org/10.1093/ ajcp/112.3.377

29. Mukunyadzi P, Liu K, Hanna EY, Suen JY, Fan CY (2003) Induced expression of syndecan-1 in the stroma of head and neck squamous cell carcinoma. Mod Pathol 16(8):796-801. https://doi. org/10.1097/01.Mp.0000081731.17549.53

30. Leivonen M, Lundin J, Nordling S, von Boguslawski K, Haglund C (2004) Prognostic value of syndecan-1 expression in breast cancer. Oncology 67(1):11-18. https://doi.org/10.1159/000080280

31. Ito Y, Yoshida H, Nakano K, Takamura Y, Miya A, Kobayashi K, Yokozawa T, Matsuzuka F, Matsuura N, Kuma K, Miyauchi A (2003) Syndecan-1 expression in thyroid carcinoma: stromal expression followed by epithelial expression is significantly correlated with dedifferentiation. Histopathology 43(2):157-164

32. Mathe M, Suba Z, Nemeth Z, Tatrai P, Fule T, Borgulya G, Barabas J, Kovalszky I (2006) Stromal syndecan-1 expression is an adverse prognostic factor in oral carcinomas. Oral Oncol 42(5):493-500. https://doi.org/10.1016/j.oraloncology.2005.10.003

33. Maeda T, Alexander CM, Friedl A (2004) Induction of syndecan-1 expression in stromal fibroblasts promotes proliferation of human breast cancer cells. Cancer Res 64(2):612-621

34. Szabo S, Xu Y, Romero R, Fule T, Karaszi K, Bhatti G, Varkonyi T, Varkonyi I, Krenacs T, Dong Z, Tarca AL, Chaiworapongsa T, Hassan SS, Papp Z, Kovalszky I, Than NG (2013) Changes of placental syndecan-1 expression in preeclampsia and HELLP syndrome. Virchows Arch 463(3):445-458. https://doi.org/10.1007/ s00428-013-1426-0

35. Fule T, Csapo Z, Mathe M, Tatrai P, Laszlo V, Papp Z, Kovalszky I (2006) Prognostic significance of high-risk HPV status in advanced cervical cancers and pelvic lymph nodes. Gynecol Oncol 100(3): 570-578. https://doi.org/10.1016/j.ygyno.2005.09.019

36. Hazelbag S, Fleuren GJ, Baelde JJ, Schuuring E, Kenter GG, Gorter A (2001) Cytokine profile of cervical cancer cells. Gynecol Oncol 83(2):235-243. https://doi.org/10.1006/gyno.2001.6378

37. Baghy K, Dezso K, Laszlo V, Fullar A, Peterfia B, Paku S, Nagy P, Schaff Z, Iozzo RV, Kovalszky I (2011) Ablation of the decorin gene enhances experimental hepatic fibrosis and impairs hepatic healing in mice. Lab Invest 91(3):439-451. https://doi.org/10. 1038/labinvest.2010.172

38. Fullar A, Dudas J, Olah L, Hollosi P, Papp Z, Sobel G, Karaszi K, Paku S, Baghy K, Kovalszky I (2015) Remodeling of extracellular matrix by normal and tumor-associated fibroblasts promotes cervical cancer progression. BMC Cancer 15:256. https://doi.org/10. 1186/s12885-015-1272-3

39. Maeda T, Desouky J, Friedl A (2006) Syndecan-1 expression by stromal fibroblasts promotes breast carcinoma growth in vivo and stimulates tumor angiogenesis. Oncogene 25(9):1408-1412. https://doi.org/10.1038/sj.onc.1209168

40. Yang N, Mosher R, Seo S, Beebe D, Friedl A (2011) Syndecan-1 in breast cancer stroma fibroblasts regulates extracellular matrix fiber organization and carcinoma cell motility. Am J Pathol 178(1):325335. https://doi.org/10.1016/j.ajpath.2010.11.039

41. Boutin EL, Sanderson RD, Bernfield M, Cunha GR (1991) Epithelial-mesenchymal interactions in uterus and vagina alter the expression of the cell surface proteoglycan, syndecan. Dev Biol 148(1):63-74. https://doi.org/10.1016/0012-1606(91)90317-v

42. Samoszuk M, Tan J, Chorn G (2005) Clonogenic growth of human breast cancer cells co-cultured in direct contact with serumactivated fibroblasts. Breast Cancer Res 7(3):R274-R283. https:// doi.org/10.1186/bcr995

43. Mise I, Vucic M (2018) Comparison of Syndecan-1 Immunohistochemical Expression in Lobular and Ductal Breast Carcinoma with Nodal Metastases. Anal Cell Pathol (Amsterdam) 2018:9432375. https://doi.org/10.1155/2018/ 9432375

44. Hashimoto Y, Skacel M, Adams JC (2008) Association of loss of epithelial syndecan-1 with stage and local metastasis of colorectal adenocarcinomas: An immunohistochemical study of clinically annotated tumors. BMC Cancer 8(1):185. https://doi.org/10.1186/ 1471-2407-8-185

45. Contreras HR, Ledezma RA, Vergara J, Cifuentes F, Barra C, Cabello P, Gallegos I, Morales B, Huidobro C, Castellon EA (2010) The expression of syndecan-1 and - 2 is associated with Gleason score and epithelial-mesenchymal transition markers, Ecadherin and beta-catenin, in prostate cancer. Urol Oncol 28(5): 534-540. https://doi.org/10.1016/j.urolonc.2009.03.018

46. Szatmari T, Otvos R, Hjerpe A, Dobra K (2015) Syndecan-1 in Cancer: Implications for Cell Signaling, Differentiation, and Prognostication. Dis Markers 2015:796052. https://doi.org/10. $1155 / 2015 / 796052$

47. Kim YI, Lee A, Lee BH, Kim SY (2011) Prognostic significance of syndecan-1 expression in cervical cancers. J Gynecol Oncol 22(3): 161-167. https://doi.org/10.3802/jgo.2011.22.3.161

Publisher's Note Springer Nature remains neutral with regard to jurisdictional claims in published maps and institutional affiliations. 